\title{
Behavioral variant of frontotemporal dementia or frontal variant of Alzheimer's disease?
}

\author{
A case study
}

\author{
Leonardo Cruz de Souza ${ }^{1,20}$, Luciano Inácio Mariano ${ }^{1}$, Renata Freire de Moraes ${ }^{3}$, Paulo Caramelli ${ }^{1,2}$
}

\begin{abstract}
Alzheimer's disease (AD) has heterogeneous clinical presentations. Amnestic progressive disorder leading to dementia is the most typical, but non-amnestic presentations are also recognized. Here we report a case of frontal variant of $A D$. A right-handed woman, aged 68 years, was referred for progressive behavioral disorders and personality changes. She had a corroborated history of dietary changes, hyperorality, impulsivity, affective indifference and apathy, with functional impairment. Cognitive assessment yielded severe executive deficits. Positron emission tomography with fluorodeoxyglucose showed marked hypometabolism in frontotemporal regions, with relative preservation of parietal regions. CSF AD biomarkers showed low $A \beta_{42}$, high Tau and high P-Tau. The patient fulfilled criteria for probable behavioral variant frontotemporal dementia. However, considering the AD pathophysiological signature on CSF biomarkers, a diagnosis of frontal variant of $A D$ was established. In the perspective of disease-modifying therapies, it is important to identify atypical Alzheimer presentations, as these patients may be candidates for specific treatments.
\end{abstract}

Key words: Alzheimer's disease, frontotemporal dementia, atypical Alzheimer's disease, biomarkers.

\section{VARIANTE COMPORTAMENTAL DA DEMÊNCIA FRONTOTEMPORAL OU VARIANTE FRONTAL DA DOENÇA DE ALZHEIMER? UM ESTUDO DE CASO}

RESUMO. A doença de Alzheimer (DA) tem apresentações clínicas heterogêneas. Amnésia progressiva associada a demência é a forma mais comum, mas apresentações não-amnésticas são também reconhecidas. Relatamos um caso de variante frontal da DA. Um mulher destra, de 68 anos, consultou-se devido a transtornos comportamentais progressivos, com alterações de personalidade. Modificações de padrão alimentar, hiperoralidade, impulsividade, indiferença afetiva e apatia, com declínio funcional, foram corroboradas pela família. A avaliação cognitiva evidenciou grave disfunção executiva. A tomografia de emissão de pósitrons com flúordeoxiglicose revelou proeminente hipometabolismo em regiões frontotemporais, com relativa preservação de regiões parietais. $A$ análise de biomarcadores de DA no líquido cefalorraquidiano mostrou redução de níveis de $A \beta_{42}$, com aumento de níveis de Tau e P-Tau. A paciente preencheu critérios diagnósticos para demência frontotemporal (variante comportamental) provável. Contudo, considerando 0 perfil de biomarcadores em favor de fisiopatologia da DA, o diagnóstico de variante frontal de DA foi estabelecido. Na perspectiva de tratamentos modificadores da doença, é crucial identificar apresentações atípicas da DA, visto que esses pacientes podem ser candidatos a terapias específicas.

Palavras-chave: doença de Alzheimer, demência frontotemporal, doença de Alzheimer atípica, biomarcadores.

$\mathrm{F}_{\mathrm{o} \text { r }}^{\mathrm{r}}$ ontotemporal dementia (FTD) is the second most common cause of early-onset dementia, presenting three main phenotypes: behavioral variant (bvFTD), non-fluent progressive aphasia and semantic dementia. ${ }^{1}$ bvFTD is the most frequent phenotype and

\footnotetext{
This study was conducted at the Programa de Pós-Graduação em Neurociências, Universidade Federal de Minas Gerais (UFMG). Belo Horizonte, MG, Brazil.

1Programa de Pós-Graduação em Neurociências, Universidade Federal de Minas Gerais (UFMG), Belo Horizonte, MG, Brazil. ²Departamento de Clínica Médica, Faculdade de Medicina, UFMG, Belo Horizonte, MG, Brazil. ${ }^{3}$ Hermes Pardini, Belo Horizonte, MG, Brazil.
}

Leonardo Cruz de Souza. Faculdade de Medicina / Universidade Federal de Minas Gerais - Avenida Professor Alfredo Balena, 190/sl 243 - 30130-100 Belo Horizonte MG - Brazil. E-mail: leocruzsouza@hotmail.com

Disclosure: The authors report no conflicts of interest.

Received February 24, 2019. Accepted in final form May 19, 2019.

(cc) BY 
is characterized by progressive behavioral and personality disorders, featuring disinhibition, apathy, loss of empathy, dietary changes, and ritualistic/stereotypical behaviors. ${ }^{2}$ bvFTD may also present cognitive deficits, with impairment in executive functions and social cognition, yet relative sparing of episodic memory and visuoconstructive abilities. ${ }^{2}$ From a pathological point of view, bvFTD is classified as frontotemporal lobe degeneration (FTLD). FTLD with tauopathy or FTLD with TAR DNA-binding protein of $43 \mathrm{kDA}$ (TDP-43) inclusions are the most common underlying findings among bvFTD patients. ${ }^{3}$ Besides FTLD pathology, bvFTD may be due to Alzheimer's pathology. ${ }^{3-5}$ Indeed, it has been recognized that the frontal ${ }^{6}$ or behavioural/dysexecutive ${ }^{5}$ variant represents an atypical presentation of Alzheimer's disease (AD). Atypical phenotypes of $\mathrm{AD}$ may be identified in vivo by pathophysiological markers, such as CSF biomarkers or amyloid imaging. ${ }^{6}$ Here, we present a case of frontal variant of $\mathrm{AD}$, with CSF Alzheimer signature.

\section{CASE REPORT}

A right-handed woman, aged 68 years, a retired bank agent with 16 years of education, was referred for neurological evaluation in 2016, for progressive behavioral disorders and personality changes evolving for approximately six months. Her family reported dietary changes, with marked preference for sweet foods. Hyperorality was also evident, with increased consumption of cigarettes. She also exhibited oral exploration, picking up inedible objects from the floor and putting them in her mouth. There was ritualistic behavior, with a tendency to repetitively clean and organize things in her house. The family reported that she became strict with time schedules. She had excessive expenses with perfumes and body creams, using them compulsively. Mild affective indifference was observed. She also manifested poor judgment abilities, with marked concrete thinking. The family reported no memory deficits or spatial disorientation, and autonomy for activities of daily living was globally preserved.

She had a depressive episode at the age of 41 , without recurrence. She had been followed by a psychiatrist over the last two years, due to anxious disorder. There was no history of hallucinations, delusions, seizures, head trauma, or alcohol abuse. She had no family history of dementia or motor neuron disease.

Neurological examination was normal, without parkinsonism or eye movement abnormalities. Myoclonus, fasciculations and muscle atrophy were absent. There were no frontal release signs.
The patient underwent two formal cognitive assessments (2016 and 2018; Table 1). Initial evaluation (2016) showed no impairment of global cognitive efficiency (Mini-Mental State Exam [MMSE]=29/30), ${ }^{7}$ with preserved time/space orientation. Performance on the Rey Auditory Verbal Learning Test (RAVLT) ${ }^{8}$ demonstrated preservation of encoding, learning, retrieval and recognition. Her performance on a visual episodic memory test ${ }^{9}$ was also normal. Planning deficits were detected on the copy of Rey complex figure and on the Tower of London test. Verbal fluencies were preserved, both in phonemic and categorical modalities. Reading

Table 1. Cognitive data.

\begin{tabular}{|c|c|c|}
\hline & 2016 & 2018 \\
\hline Mini-Mental State Exam ( /30) & 29 & 26 \\
\hline - Time Orientation (/5) & 5 & 4 \\
\hline - Space Orientation (/5) & 5 & 5 \\
\hline - Immediate Memory (/3) & 3 & 3 \\
\hline - Calculation (/5) & 4 & 4 \\
\hline - Recall (/3) & 3 & 1 \\
\hline - Language (/8) & 8 & 8 \\
\hline - Drawing (/1) & 1 & 1 \\
\hline Rey Auditory Verbal Learning Test (RAVLT) - A1 (/15) & 5 & 3 \\
\hline Rey Auditory Verbal Learning Test (RAVLT) - A2 (/15) & 7 & 7 \\
\hline Rey Auditory Verbal Learning Test (RAVLT) - A3 (/15) & 10 & 7 \\
\hline Rey Auditory Verbal Learning Test (RAVLT) - A4 (/15) & 12 & 9 \\
\hline Rey Auditory Verbal Learning Test (RAVLT) - A5 (/15) & 12 & 10 \\
\hline Rey Auditory Verbal Learning Test (RAVLT) - B1 (/15) & 3 & 2 \\
\hline Rey Auditory Verbal Learning Test (RAVLT) - A6 ( /15) & 11 & 9 \\
\hline Rey Auditory Verbal Learning Test (RAVLT) - A7 (/15) & 13 & 7 \\
\hline Rey Auditory Verbal Learning Test (RAVLT) - Recognition (/15) & 13 & 4 \\
\hline Rey Auditory Verbal Learning Test (RAVLT) - Sum A1-A7 & 46 & 36 \\
\hline Figures Memory Test (Incidental) (/10) & 6 & 6 \\
\hline Figures Memory Test (Immediate) (/10) & 10 & 8 \\
\hline Figures Memory Test (Learning) (/10) & 10 & 8 \\
\hline Figures Memory Test (5-minute recall) (/10) & 10 & 7 \\
\hline Figures Memory Test (Recognition) (/10) & 10 & 10 \\
\hline Rey-0sterrieth Complex Figure Test (Copy) & 25 & 35 \\
\hline Rey-0sterrieth Complex Figure Test (Recall) & 14 & 4 \\
\hline Tower of London & 26 & 26 \\
\hline Letter Fluencies ( $F, A, S)$ & 35 & 37 \\
\hline Categorical fluency (Animals) & 14 & 10 \\
\hline Categorical fluency (Fruits) & 14 & 17 \\
\hline
\end{tabular}


Table 2. Social Cognition Assessment (August 2018).

\begin{tabular}{|c|c|}
\hline Test & $\begin{array}{l}\text { Raw } \\
\text { score }\end{array}$ \\
\hline Faux-Pas Test: Total Score ( /40) & 38 \\
\hline - Stories with Faux-Pas ( /30) & 28 \\
\hline - Stories without Faux-Pas ( /10) & 10 \\
\hline - Faux-Pas Test-Comprehension ( /10) & 10 \\
\hline False-Belief Test (Theory of mind - 15): total score ( /15) & 12 \\
\hline - False-Belief Test (Theory of mind - 15): first order ( /8) & 7 \\
\hline - False-Belief Test (Theory of mind - 15): second order ( /7) & 5 \\
\hline - False-Belief Test (Theory of mind - 15): comprehension ( /15) & 15 \\
\hline Facial Emotion Recognition Test - Total score ( /35) & 28 \\
\hline - Facial Emotion Recognition Test - Happiness ( / 5) & 5 \\
\hline - Facial Emotion Recognition Test - Surprise ( / 5) & 5 \\
\hline - Facial Emotion Recognition Test - Disgust ( / 5) & 5 \\
\hline - Facial Emotion Recognition Test - Fear ( / 5) & 0 \\
\hline - Facial Emotion Recognition Test - Anger ( / 5) & 5 \\
\hline - Facial Emotion Recognition Test - Sadness ( / 5) & 4 \\
\hline - Facial Emotion Recognition Test - Neutral ( / 5) & 4 \\
\hline
\end{tabular}

and writing abilities were spared, with preserved comprehension of written language.

In 2018, the patient had subnormal performance on the MMSE (26/30). The performance on the Mattis scale ${ }^{10}$ was normal (142/144), but global cognitive efficiency was impaired (79/100) on the Addenbrooke Cognitive Examination - Revised Version (ACE-R), ${ }^{11}$ due to significant deficits in verbal fluency and figure naming, with relative preservation on memory tests. Scores on the RAVLT were markedly worse than in 2016. Similarly, scores on the visual episodic memory test ${ }^{9}$ were also worse than previously. Performances on verbal fluencies remained globally stable. Flexibility and conceptualization were impaired on the modified Wisconsin Card Sorting Test. ${ }^{12}$ The patient presented attentional and working memory impairments, and also deficits of inhibitory control on the Hayling test. In summary, she exhibited a full dysexecutive syndrome.

This second cognitive assessment also included tests of social cognition (Table 2). The patient had normal performance on two tests of theory of mind, the fauxpas test from the Social and Emotional Assessment ${ }^{13}$ and the Theory of Mind - 15 (TOM-15), a false-belief test. ${ }^{14}$ The total score on the emotion recognition test ${ }^{15}$ was normal (28/35), but she had marked deficit in the recognition of fear (0 out 5 ).
The patient underwent a complete blood exam in order to exclude causes of non-neurodegenerative dementias, without abnormalities.

Brain MRI (January/2017) revealed mild parietal atrophy, without medial temporal or frontotemporal atrophy. The patient underwent another brain MRI thirteen months later (February/2018), which disclosed a similar pattern, but with more pronounced parietal atrophy (Figure 1A). There were moderate periventricular white matter lesions (Fazekas 2 - Figure 1B). The burden and topography of these lesions were considered very unlikely to be the cause of the full behavioral syndrome, especially impulsivity, hyperorality, ritualistic behavior and dietary changes.

Positron emission tomography with fluorodeoxyglucose ([PET-FDG] - November/2018) showed marked hypometabolism in temporal poles and the anterior cingulate (Figure 1B). There was mild hypometabolism in orbitofrontal cortex, medial temporal regions (including hippocampus) and temporo-parietal cortex. Importantly, there was no hypometabolism in the precuneus and posterior cingulate.

Lumbar puncture was performed for clinical purposes and routine analysis was unremarkable. CSF AD biomarkers were measured and showed low $\mathrm{A} \beta_{42}$ (289 $\mathrm{pg} / \mathrm{mL}$; cut-off $>600 \mathrm{pg} / \mathrm{mL})$, high Tau $(473 \mathrm{pg} / \mathrm{mL}$; cutoff $<350 \mathrm{pg} / \mathrm{mL}$ ) and high P-Tau (74 pg/mL; cut-off $<60$ $\mathrm{pg} / \mathrm{mL}$ ), in favor of an $\mathrm{AD}$ pathophysiological process.

During a 24-month clinical follow-up, there was deterioration in cognitive abilities and mild loss of autonomy (Pfeffer Functional Activities Questionnaire $=9 / 30$ ). She had taken out a large financial loan, and the family had to take control of her finances. The patient clinically developed severe apathy (Starkstein Apathy Scale=32/42) and reduced personal hygiene. The patient has been treated with antipsychotics for behavioral control. Treatment with cholinesterase inhibitors was introduced, without clinical improvement.

The patient fulfills criteria for probable bvFTD according to consensus diagnostic criteria: ${ }^{2} 1$ ) a corroborated history of initial progressive behavioral and personality changes, with dietary changes, hyperorality, impulsivity, ritualistic behavior, affective indifference and apathy; (2) presence of severe executive deficits; 3) marked hypometabolism on PET-FDG in frontotemporal regions (temporal poles, anterior cingulate), with relative preservation of parietal regions; 4) Functional impairment. Considering the $\mathrm{AD}$ pathophysiological signature on CSF biomarkers, a diagnosis of frontal variant of $\mathrm{AD}$ was established. 

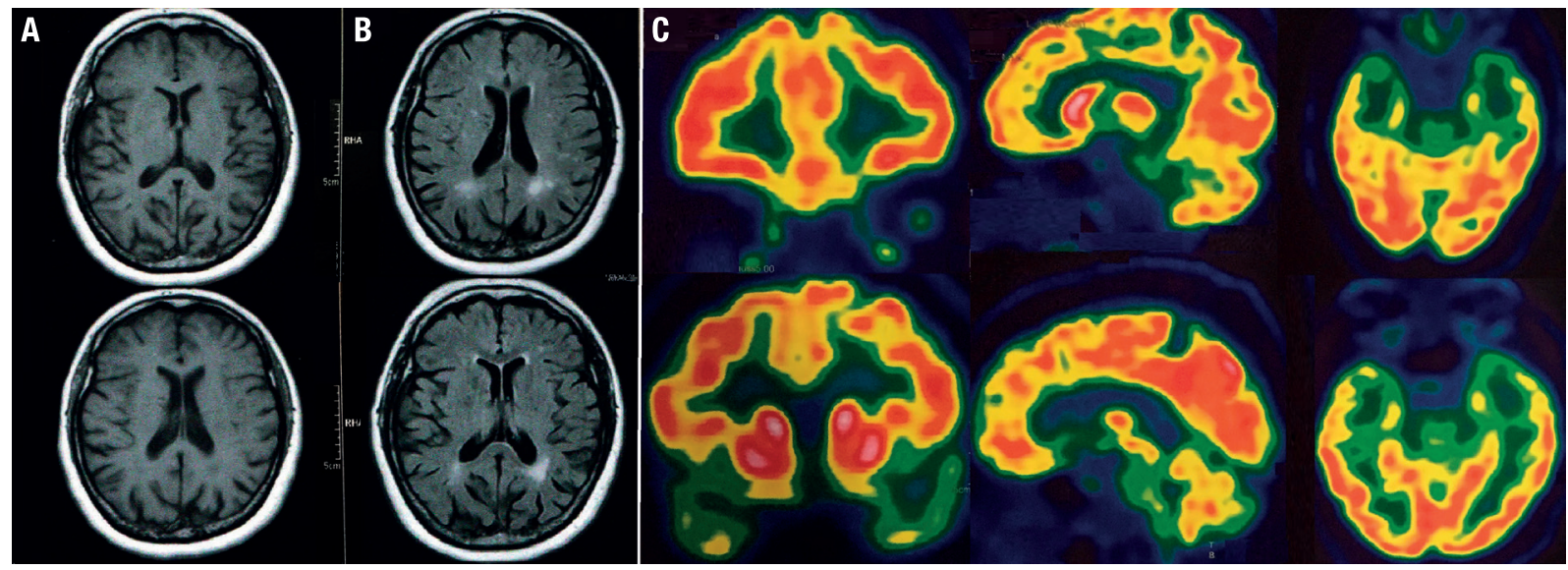

Figure 1. A. Magnetic resonance imaging (MRI) of brain showing moderate parietal atrophy and no focal frontotemporal atrophy. B. Moderate white matter disease on brain MRI. C. Positron emission tomography with fluorodeoxyglucose (PET-FDG) showing marked hypometabolism in temporal poles and anterior cingulate; there is mild hypometabolism in the orbitofrontal cortex, medial temporal regions (including hippocampus) and temporo-parietal cortex. No hypometabolism is evident in the precuneus and posterior cingulate.

\section{DISCUSSION}

$\mathrm{AD}$ has heterogeneous clinical presentations. Amnestic progressive disorder leading to dementia is the most typical, ${ }^{16}$ but non-amnestic presentations, such as posteriorcorticalatrophy,logopenicaphasiaandfrontalvariant, are also recognized. ${ }^{6}$ Here, we report a patient fulfilling consensus criteria for probable bvFTD, but presenting CSF biomarker evidence of underlying Alzheimer's pathophysiology. According to the recently proposed biological definition of $A D,{ }^{17}$ the patient can be classified as A+ (abnormal CSF A $\beta_{42}$ ), T+ (abnormal CSF P-Tau) and $(\mathrm{N})+$ (hypometabolism on PET-FDG and abnormal CSF Tau), thus meeting criteria for Alzheimer's continuum. ${ }^{17}$

The frequency of frontal variant of $\mathrm{AD}$ is unknown. Most clinicopathological studies have found that bvFTD is rarely associated to Alzheimer pathology. ${ }^{3,18}$ However, it should be pointed out that comorbid Alzheimer-related pathological changes may be observed in bvFTD patients with confirmed FTLD. ${ }^{19,20}$ Therefore, it is possible that the Alzheimer CSF biological signature in our patient is due to comorbid association between AD and FTLD.

Patients with Alzheimer variants are usually younger than patients with typical AD. In the present case, behavioral symptoms started after the age of 65 years; clinicians should be aware of atypical Alzheimer presentations even in older subjects.

Patients with atypical Alzheimer presentations do not exhibit typical distribution of neurofibrillary pathology, initially involving transentorhinal cortex, hippocampus and then spreading through association cortices. ${ }^{16}$ On the contrary, it has been demonstrated that patients with frontal variant of $\mathrm{AD}$ have greater pathological findings in frontal regions than typical AD. ${ }^{21-23}$ Molecular neuroimaging studies with tau mark- ers reinforce that there are distinct topographical patterns of neurodegeneration across different presentations of $\mathrm{AD}{ }^{24}$

There is an overlap of cognitive deficits between bvFTD due to FTLD and frontal variant of AD. Although data exists suggesting that patients with behavioral $A D$ have worse performance on episodic memory tests than bvFTDFTLD patients, ${ }^{5}$ frank amnesia may also be observed in bvFTD. ${ }^{25}$ Our patient had normal scores on both visual and verbal episodic memory tests on the first cognitive assessment, but her performance declined over time.

Deficits in facial emotion recognition, theory of mind and knowledge of social norms have been reported in patients with frontal variant of $A D,{ }^{26,27}$ rendering it difficult to differentiate from bvFTD-FTLD. In the present case, the patient had isolated deficit in fear recognition. There was no deficit on theory of mind tasks. More studies are warranted to investigate social cognition in patients with frontal $\mathrm{AD}$, and to assess the diagnostic accuracy of social cognition tests in the differential diagnosis between frontal $\mathrm{AD}$ and bvFTD.

Neuroimaging is a crucial tool in the investigation of cognitive-behavioral disorders, as specific atrophic patterns are associated with distinct clinical diagnoses. Compared to bvFTD-FTLD, patients with behavioral/ dysexecutive variant of $\mathrm{AD}$ have greater parietal atrophy. ${ }^{5}$ Our patient had posterior involvement on brain $\mathrm{MRI}$, thus supporting the diagnosis of atypical AD. However, she did not exhibit hypometabolism in the precuneus or posterior cingulate, which has been found in behavioral/dysexecutive variant. ${ }^{5}$ Conversely, she had marked hypometabolism in temporal poles and anterior cingulate, with mild involvement of the orbitofrontal cortex. These findings are commonly observed in bvFTD 
and are closely related to the patient's behavioral symptoms (apathy, impulsivity, dietary changes). We consider that functional neuroimaging is a helpful tool to elucidate behavioral symptoms in patients with normal or borderline findings on structural imaging.

In summary, the present report illustrates the phenotypical heterogeneity of AD. Atypical Alzheimer variants represent a clinical diagnostic challenge. In the perspective of treatments targeting amyloidosis and Alzheimer-related tauopathy, it is important to identify atypical Alzheimer presentations such as frontal variant, as these patients may be candidates for specific diseasemodifying treatments.

Author contributions. LCS: clinically assessed the patient and drafted the first version of the manuscript. LIM: performed cognitive assessment of the patient and critically reviewed the manuscript for intellectual content.
RFM: conducted functional neuroimaging investigation and critically reviewed the manuscript for intellectual content. PC: critically reviewed the manuscript for intellectual content.

Acknowledgements. We are greatly indebted to the family of our patient for their willingness to participate and interest in the scientific study. We thank Ms. Melissa Andréia da Costa e Silva for initial cognitive assessment of the patient. We thank the reviewers for their critical insights on the first version of the manuscript.

Ethical statement. Informed consent was obtained from the patient's family for the case report.

Support. LCS and PC are supported by the Brazilian National Council for Scientific and Technological Development ( $\mathrm{CNPq}$ - bolsa de produtividade em pesquisa).

\section{REFERENCES}

1. Bang J, Spina S, Miller BL. Frontotemporal dementia. Lancet. 2015; 386(10004):1672-82.

2. Rascovsky K, Hodges JR, Knopman D, Mendez MF, Kramer JH, Neuhaus J, et al. Sensitivity of revised diagnostic criteria for the behavioural variant of frontotemporal dementia. Brain. 2011;134(Pt 9):2456-77.

3. Perry DC, Brown JA, Possin KL, Datta S, Trujillo A, Radke A, et al. Clinicopathological correlations in behavioural variant frontotemporal dementia. Brain. 2017;140(12):3329-45.

4. Mendez MF, Joshi A, Tassniyom K, Teng E, Shapira JS. Clinicopathologic differences among patients with behavioral variant frontotemporal dementia. Neurology. 2013;80(6):561-8.

5. Ossenkoppele R, Pijnenburg YA, Perry DC, Cohn-Sheehy BI, Scheltens NM, Vogel JW, et al. The behavioural/dysexecutive variant of Alzheimer's disease: clinical, neuroimaging and pathological features. Brain. 2015;138(Pt 9):2732-49.

6. Dubois B, Feldman HH, Jacova C, Hampel H, Molinuevo JL, Blennow $\mathrm{K}$, et al. Advancing research diagnostic criteria for Alzheimer's disease: the IWG-2 criteria. Lancet Neurol. 2014;13(6):614-29.

7. Brucki SM, Nitrini R, Caramelli P, Bertolucci PH, Okamoto IH. Suggestions for utilization of the mini-mental state examination in Brazil. Arq Neuropsiquiatr. 2003;61(3B):777-81.

8. Malloy-Diniz LF, Lasmar VA, Gazinelli Lde S, Fuentes D, Salgado JV. The Rey Auditory-Verbal Learning Test: applicability for the Brazilian elderly population. Rev Bras Psiquiatr. 2007;29(4):324-9.

9. Nitrini R, Caramelli P, Herrera Júnior E, Porto CS, Charchat-Fichman H, Carthery MT, et al. Performance of illiterate and literate nondemented elderly subjects in two tests of long-term memory. J Int Neuropsychol Soc. 2004;10(4):634-8.

10. Porto CS, Fichman HC, Caramelli P, Bahia VS, Nitrini R. Brazilian version of the Mattis dementia rating scale: diagnosis of mild dementia in Alzheimer's disease. Arq Neuropsiquiatr. 2003;61(2B):339-45.

11. Amaral-Carvalho V, Caramelli P. Normative data for healthy middle-aged and elderly performance on the Addenbrooke Cognitive ExaminationRevised. Cogn Behav Neurol. 2012;25(2):72-6.

12. Nelson HE. A modified card sorting test sensitive to frontal lobe defects. Cortex. 1976; 12(4):313-24

13. Funkiewiez A, Bertoux M, de Souza LC, Levy R, Dubois B. The SEA (Social cognition and Emotional Assessment): a clinical neuropsychological tool for early diagnosis of frontal variant of frontotemporal lobar degeneration. Neuropsychology. 2012;26(1):81-90.

14. Desgranges B, Laisney M, Bon L, Duval C, Mondou A, Bejanin A, et al TOM-15: Une épreuve de fausses croyances pour évaluer la théorie de l'esprit cognitive. Rev Neuropsychol. 2012;4(3):216-20.
15. de Souza LC, Bertoux M, de Faria ARV, Corgosinho LTS, de Almeida Prado AC, Barbosa IG, et al. The effects of gender, age, schooling, and cultural background on the identification of facial emotions: a transcultural study. Int Psychogeriatr. 2018:30(12):1861-70.

16. Murray ME, Graff-Radford NR, Ross OA, Petersen RC, Duara R, Dickson DW. Neuropathologically defined subtypes of Alzheimer's disease with distinct clinical characteristics: a retrospective study. Lancet Neurol. 2011;10(9):785-96.

17. Jack CR Jr, Bennett DA, Blennow K, Carrillo MC, Dunn B, Haeberlein SB, et al. NIA-AA Research Framework: Toward a biological definition of Alzheimer's disease. Alzheimers Dement. 2018;14(4):535-62.

18. Alladi S, Xuereb J, Bak T, Nestor P, Knibb J, Patterson K, Hodges JR. Focal cortical presentations of Alzheimer's disease. Brain. 2007;130(Pt 10):2636-45.

19. Liscic RM, Storandt M, Cairns NJ, Morris JC. Clinical and psychometric distinction of frontotemporal and Alzheimer dementias. Arch Neurol. 2007;64(4):535-40.

20. Seo SW, Thibodeau MP, Perry DC, Hua A, Sidhu M, Sible I, et al. Early vs late age at onset frontotemporal dementia and frontotemporal lobar degeneration. Neurology. 2018;90(12):e1047-e56.

21. Herrero-San Martin A, Villarejo-Galende A, Rabano-Gutierrez A, Guerrero-Marquez C, Porta-Etessam J, Bermejo-Pareja F. [Frontal variant of Alzheimer's disease. Two pathologically confirmed cases and a literature review]. Rev Neurol. 2013;57(12):542-8.

22. Blennerhassett R, Lillo P, Halliday GM, Hodges JR, Kril JJ. Distribution of pathology in frontal variant Alzheimer's disease. J Alzheimers Dis. 2014;39(1):63-70.

23. Kawakatsu S, Kobayashi R, Hayashi H. Typical and atypical appearance of early-onset Alzheimer's disease: A clinical, neuroimaging and neuropathological study. Neuropathology 2017;37(2):150-73.

24. Ossenkoppele R, Schonhaut DR, Schöll M, Lockhart SN, Ayakta N, Baker SL, et al. Tau PET patterns mirror clinical and neuroanatomical variability in Alzheimer's disease. Brain 2016;139(Pt 5):1551-67.

25. Hornberger M, Piguet $\mathrm{O}$. Episodic memory in frontotemporal dementia: a critical review. Brain 2012;135(Pt 3):678-92.

26. de Souza LC, Bertoux M, Funkiewiez A, Samri D, Azuar C, Habert MO, et al. Frontal presentation of Alzheimer's disease: a series of patients with biological evidence by CSF biomarkers Dement Neuropsychol 2013;7(1):66-74

27. Duclos H, de La Sayette V, Bonnet AL, Viard A, Eustache F, Desgranges B, Laisney M. Social Cognition in the Frontal Variant of Alzheimer's Disease: A Case Study. J Alzheimers Dis 2017;55(2):459-63. 